\title{
Seasonal Variations of Cell Site Diversity Gain
}

\author{
Sharmini Enoch ${ }^{\# 1}$, Ifiok Otung ${ }^{\# 2}$ \\ 1-Doctors Academy, \\ Cardiff, CF14 3JR, South Glamorgan, United Kingdom \\ sharminienoch@gmail.com \\ 2- University of South Wales, \\ Pontypridd, Wales, UK \\ ifiok.otung@southwales.ac.uk
}

\begin{abstract}
The broadband fixed wireless access (BFWA) systems operate in microwave frequencies. In this frequency range, the wave propagation is highly influenced by precipitation caused especially by rain. With the use of cell site diversity (CSD), the rain attenuation effects can be mitigated. When the signal level falls below a certain threshold the subscriber station switches to another base station within the coverage area. This paper aims at demonstrating the performance improvements obtained with the use of cell site diversity during various seasons for measurements carried out from HYREX rain gauge network in UK. The parameters traditionally used to quantify cell site diversity are CSD gain and diversity improvement. This paper analyzes the CSD gain achieved. The gain increases with increasing frequency and distance. The link performance is compared for various seasons and the results show that the maximum attenuation occurs during summer, while the least attenuation occurs during winter. Therefore, maximum gain of up to $22 \mathrm{~dB}$ occurs at $54 \mathrm{GHz}$ frequency during winter. The second observation is that when the angular separation between the diversity sites is $180^{\circ}$ separation there is maximum gain for all seasons.
\end{abstract}

Keywords - Cell site diversity, diversity improvement, fade mitigation, WiMAX

\section{INTRODUCTION}

The WiMAX technique is aimed at provision of quality services to end users with high data rate and wide coverage. The channel capacity or data rate is limited by the bandwidth, transmission power, noise, distortion and interference [1]. The WiMAX uses frequencies between 2 and $66 \mathrm{GHz}$. It specifies a range of 30 miles for channel bandwidths from $1.75 \mathrm{MHz}$ to $20 \mathrm{MHz}$ [2]. The operating link has a fixed or mobile subscriber station (SS) and a base station (BS) that connects to a wired network.

Above the $10 \mathrm{GHz}$ frequency range, rainfall can cause considerable attenuation in the received signal [3]. For planning and designing high capacity point-to-point and point-to-multipoint radio systems above 2 $\mathrm{GHz}$ frequency band, the accurate prediction of rain attenuation in the terrestrial links is essential. Mainly based on experimental data, several empirical and semi-empirical rain attenuation prediction methods have been proposed over the years. The widely used predicting models currently are the ITU-R model and the Crane model [4]. The ITU-R.838-3 predicts the effect of rain attenuation in the terrestrial link. The rain attenuation increases with the length of the radio link and depends on the rainfall climatic conditions in the region where the link has to be installed for a given frequency and polarization [3].

\section{CSD SETUP FOR WIMAX LINK}

When designing a WiMAX network above $10 \mathrm{GHz}$, the major concern is the provision of clear LOS path between the base stations and subscriber stations. In the absence of LOS, the effects of scattering, diffraction and shadowing from buildings and vegetation lead to considerable power loss. In order to achieve LOS and overcome power loss, highly directive antennas are employed in the SSs at this frequency band. Attenuation due to precipitation is significant due to this reason, whilst, comparatively multipath propagation is insignificant. Considering the spatial nature of the rainfall, cell site diversity technique is helpful as high intensity rain is confined to a smaller area. When the rain event occurs on the path of the base station that provides default service to the subscriber, an alternate base station can take over the connection, provided it is not affected by rain. The receiving antennas are located at various BS sites in a CSD design.

Taking into account the inhomogeneous nature of rain using two links to lessen the effect of rain attenuation, was first proposed by Hogg [5]. The aim is to calculate the service availability improvement using cell site diversity. The subscriber station needs highly directional antennas that minimize the number of multipath and interference from unexpected sources in order to achieve high quality and availability during LOS radio 
propagation conditions between the subscriber station and the base stations. Inter-symbol interference is produced due to the occurrence of multipath.

In Fig. 1, the CSD configuration is shown. It consists of four base stations A, B, C, D and one subscriber station taking different paths, where the angular separation ranges from $0^{\circ}$ to $360^{\circ}$. The subscriber station is assigned to a reference base station, which is located in the same cell and three diversity stations each located in different neighboring cells in order to provide cell site diversity. The angular separation between each link ranges from $0^{\circ}$ to $90^{\circ}$.

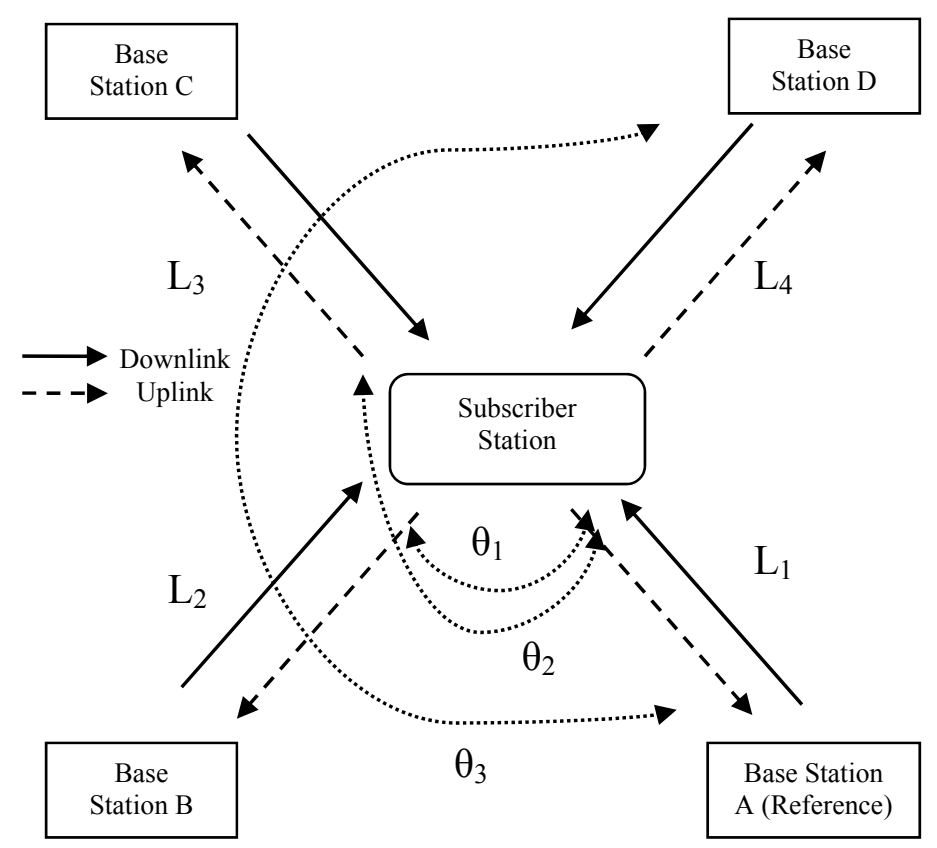

Fig. 1. Typical scenario for Cell site diversity

In Fig. 1, the distances between BS's A, B, C, D to the SS are represented as $\mathrm{L}_{1}, \mathrm{~L}_{2}, \mathrm{~L}_{3}$ and $\mathrm{L}_{4}$ respectively. Angular separation is the measure of the azimuth angle ' $\theta$ ' separating the diversity sites. The angular separations are considered with respect to the reference base station $\mathrm{A}$. It is represented as $\theta_{1}$ between BSs A and $\mathrm{B}, \theta_{2}$ between BSs A and C, $\theta_{3}$ between BSs A and D.

\section{A. Diversity gain and diversity improvement computation}

The two measures of diversity are diversity gain and diversity improvement. The measure of the reduction in the fade margin or an increase in the average signal value is the diversity gain. It is defined as the difference between the attenuation exceeded at a certain percentage of time for a single link and the attenuation exceeded at a certain percentage of time for a joint link. The diversity gain $G(p)$ at percentage of time 'p' can be obtained as follows:

$$
\mathrm{G}(\mathrm{p})=\mathrm{A}(\mathrm{p})-\mathrm{A}_{\mathrm{d}}(\mathrm{p})(d B)
$$

Where $A_{d}(p)$ is the fade depth in the combined diversity (joint) path, and $A(p)$ is the fade depth for the unprotected (single) path occurring in time percentage ' $t$ '. Each sample $A_{d}$ of the four-link attenuation for diversity with selection combining is computed as:

$$
A_{d}(p)=\min \left[\left(A_{r e f}(t), A_{i}(t)\right](d B)\right.
$$

Where, $\mathrm{A}_{\text {ref }}(\mathrm{t})$ and $\mathrm{A}_{\mathrm{i}}(\mathrm{t})$ are the instantaneous rain attenuation values at the reference site and diversity sites respectively.

The measure of the increase in system availability is the diversity improvement, I(A). It is defined as the ratio of the single link to the joint link probabilities, for a given fade depth. 


$$
I(A)=\frac{P(A)}{P_{d}(A)}
$$

$\mathrm{P}(\mathrm{A})$ is the time percentage for the unprotected path and $\mathrm{P}_{\mathrm{d}}(\mathrm{A})$ is the percentage of time in the combined diversity path with a fade depth larger than $\mathrm{A}(\mathrm{dB})$. Usually gain is preferred to the improvement because of its higher statistical confidence even though both gain and the improvement describe diversity completely. This is because the same amount of observation time is used for both the single distribution and for the joint distributions [6].

\section{HYREX RAINGAUGE MEASUREMENT SETUP}

In 1993 to examine the variation of spatial rainfall structure, the Hydrological Radar Experiment (HYREX) rain gauge network was set up. Dense rain gauges were set up in the Brue catchments in Lovington, Somerset, England as part of the campaign. The network consisted of 49 rain gauges, with separations ranging from approximately $600 \mathrm{~m}$ to $14.5 \mathrm{~km}$. The location is a valley characterized by varying ground height above the mean sea level ranging from $40 \mathrm{~m}$ to $210 \mathrm{~m} \mathrm{[7].}$

A Casella tipping bucket rain gauge of $0.2 \mathrm{~mm}$ was used, which consists of a divided bucket placed at a pivoted centre. Water was collected on one side of the bucket and tips occur when the collected water level reached $0.2 \mathrm{~mm}$. The collected amount of water was discharged and the other half of the bucket was positioned for filling as a tip occurred. For all the 49 gauges, the data was recorded with a time resolution of 10 seconds and stored on a monthly basis. The measurements were carried out for four years.

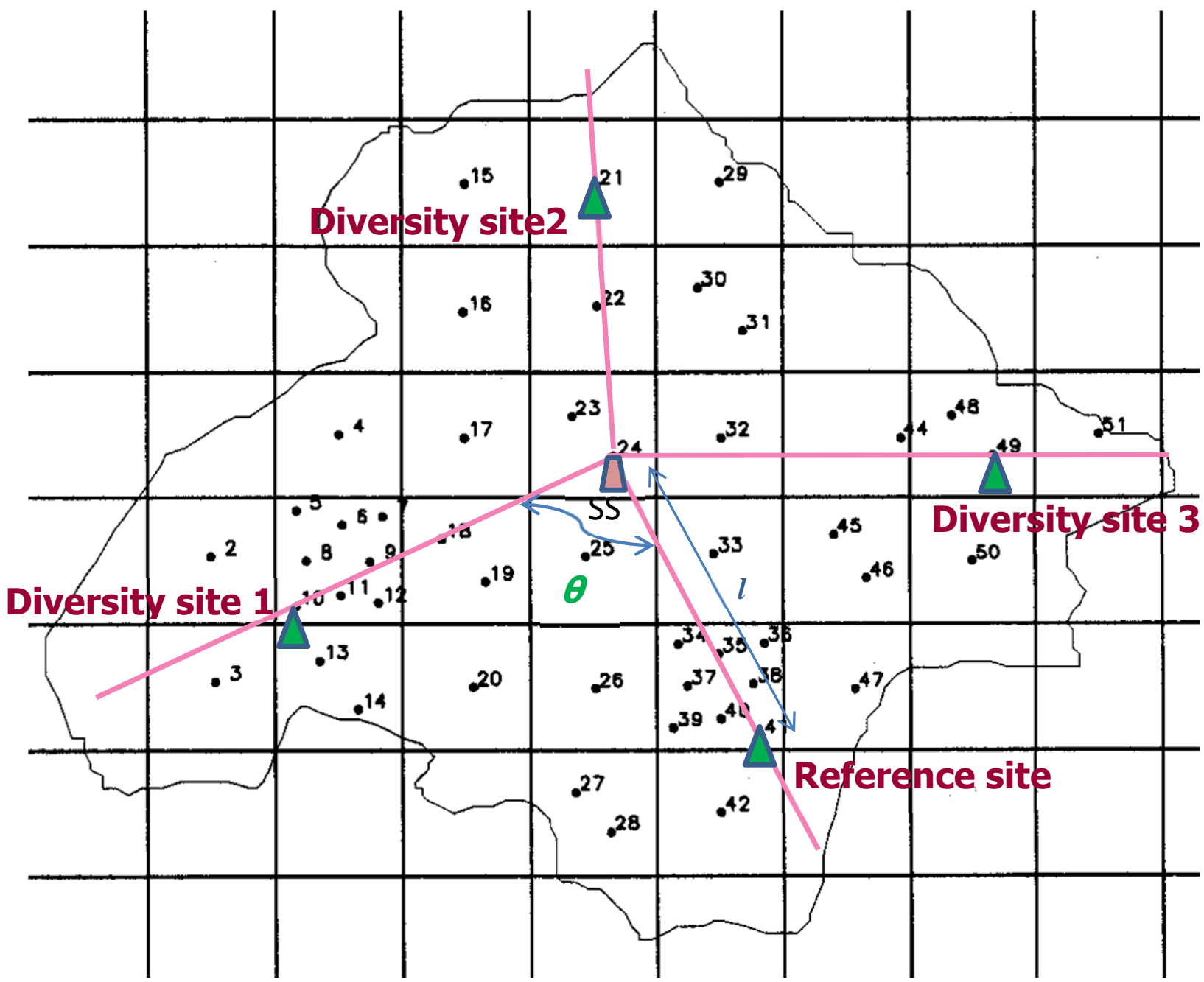

Fig. 2. The HYREX dense rain gauge network over the Brue catchment

The rain gauge data from HYREX are taken such that the base stations are located along four directions at points 21, 10, 41 and 49 for implementing the CSD technique as shown in Fig. 2. The subscriber station is located at point 24 . 


\section{RAIN ATTENUATION ANALYSIS}

The data obtained during 1999 from various rain gauges is analyzed. Data from the gauges of the above network are taken every 10 seconds. The rain rate thus obtained is then averaged over 30 samples to yield 5 minutes integrated rain. Using ITU-R P.838 and P.530, the rain attenuation computation is carried out [8] [9]. The 5-minute rain rates $\left(\mathrm{R}_{\mathrm{p}}, \mathrm{mm} / \mathrm{hr}\right)$ obtained from the rain gauge data are used to compute the total path rain attenuation at time, ' $\mathrm{t}$ ' $\left(\mathrm{A}_{\mathrm{t}}, \mathrm{dB}\right)$. It is computed as the sum of rain attenuations of individual points located along the path.

$$
A_{t}=k \sum_{i=1}^{n} L_{k} R_{k}^{\alpha}(t)(d B)
$$

Where, ' $k$ ' and ' $\alpha$ ' are the link frequency dependent coefficients obtained from ITU-R. ' $L_{k}$ ' is the length of the $\mathrm{k}^{\text {th }}$ hop along the path, and $\mathrm{n}$ is the number of hops.

In the absence of a rain gauge in the vicinity of the path, the linear interpolation is used to obtain the rain rate of a point in the path. The rain rate is computed from the rain rates of more than one rain gauge by using a factor ' $\mathrm{x}$ '. This factor is based on the distance of the rain gauge from the path. For example, if rain gauge ' $A$ ' lies at a distance ' $\mathrm{x}_{1}$ ', $\mathrm{km}$ from the path and rain gauge ' $\mathrm{B}$ ' lies at a distance of ' $\mathrm{x}_{2}$ ', $\mathrm{km}$ from the path and when $\mathrm{x}_{1} \neq \mathrm{x}_{2}$, then the point rain rate $\left(\mathrm{R}_{\mathrm{p}}\right)$ is computed as:

$$
R_{p}=\frac{x_{2} R_{1}}{x_{1}+x_{2}}+\frac{x_{1} R_{2}}{x_{1}+x_{2}}(\mathrm{~mm} / \mathrm{hr})
$$

when $\mathrm{x}_{1}=\mathrm{x}_{2}$, eq. (5) is reduced to:

$$
R_{p}=\frac{R_{1}+R_{2}}{2}(\mathrm{~mm} / \mathrm{hr})
$$

Where, ' $R_{1}$ ' and ' $R_{2}$ ' are the rain rates in rain gauges ' $A$ ' and ' $B$ '.

The cumulative distribution for point rainfall rate and attenuation for the SS is plotted in Fig. 3. The rain rate exceeds $22 \mathrm{~mm} / \mathrm{hr}$ for $0.01 \%$ of time and attenuation exceeds $2 \mathrm{~dB}$ for the same time. The rain attenuation computation and plotting are carried out using MATLAB.

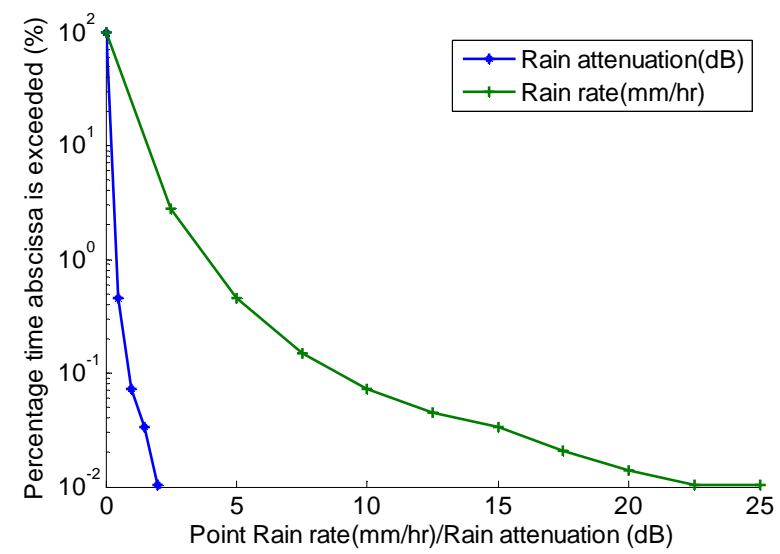

Fig. 3. Cumulative distribution of rain rate and attenuation for one year data

\section{A. Diversity Improvement}

The precipitation varies considerably in time and in space both vertically and horizontally. The improvement achieved in availability is found by using two or more base stations at any instant of time. Since the spatial distribution of rain cells depend on their temporal resolution (convective events are localized whereas stratiform events are wide-spread) the attenuation statistics for a single path and two joint diversity paths $(2 \mathrm{~km}$ paths) with angular separation varies from $0^{\circ}$ to $90^{\circ}$. The smallest attenuation occurring simultaneously on these two paths is the joint path attenuation.

The diversity improvement along with diversity gain with the use of joint links compared with a single link is shown in Fig. 4. At $0.05 \%$ of time, a diversity gain (gain improvements in $\mathrm{x}$-axis) of $1.1 \mathrm{~dB}$ is achieved with the use of joint sites as compared with no diversity. As time percentages lowers, the diversity improvement factor increases along with diversity gain. 


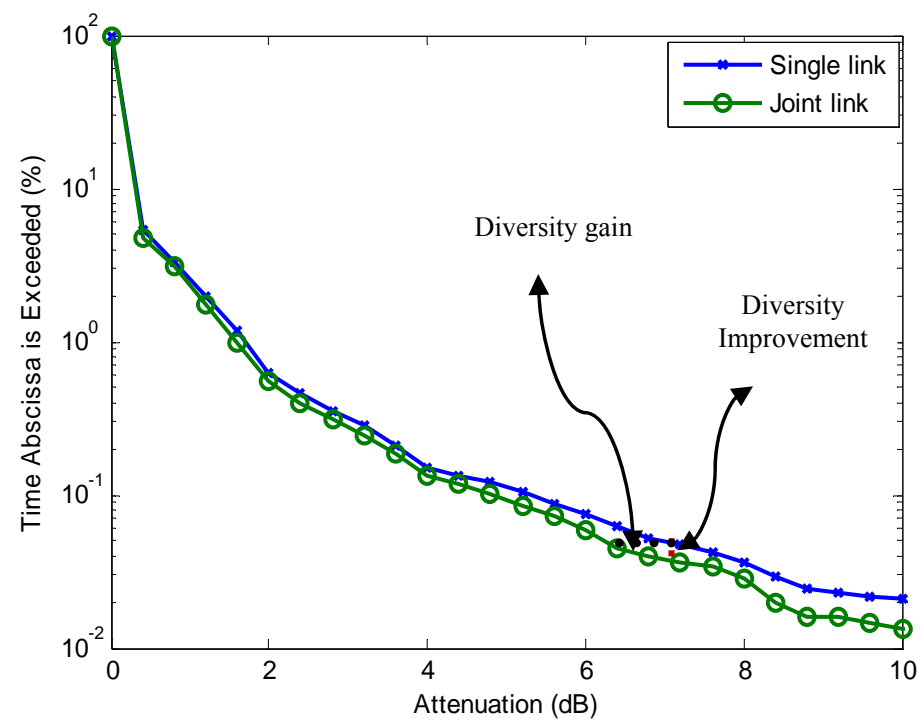

Fig. 4. Graph indicating performance improvement of joint link compared with single link at $42 \mathrm{GHz}$ at $2 \mathrm{~km}$

\section{SEASONAL DISTRIBUTION OF CELL SITE DIVERSITY GAIN}

\section{A. Seasonal analysis of CSD gain}

The seasonal information from the data is gathered and the CSD gain is determined at various seasons. According to the four seasons, the $A_{\text {ref }}(t)$ and $A_{i}(t)$ time series are grouped and sorted to obtain the seasonal as well as overall CDF of gain for each diversity system setup corresponding to a unique set of angular separation and separation distance values.

The seasonal CSD gain with the variation of angular separation between the sites is also determined. The diversity sites are chosen to achieve seven separate angular separations of $45^{\circ}, 90^{\circ}, 130^{\circ}, 180^{\circ}, 225^{\circ}, 270^{\circ}$, and $315^{\circ}$ along each of which the site separation was varied between two and five kilometres. This resulted in seven groups of diversity stations corresponding to the seven angular separations. Finally, a single CDF was obtained overall for each season by averaging over the individual CDFs of each period.

\section{B. Seasonal observations}

Fig. 5 plots the CDF of attenuation during different seasons of an year along with the annual attenuation and the corresponding diversity gains respectively. There is significant variation in overall fade levels in various seasons of a year.

For the measurements made during 1999, the Fig. 5 (a) suggests that the maximum attenuation occurs during summer, while the least attenuation occurs during winter. The overall attenuation is $39 \mathrm{~dB}$ during summer, 30 $\mathrm{dB}$ during spring, $25 \mathrm{~dB}$ during autumn and $24 \mathrm{~dB}$ during winter for $0.01 \%$ of a year. This leads to highest CSD gain of upto $22 \mathrm{~dB}$ during winter, $21 \mathrm{~dB}$ during autumn, $20 \mathrm{~dB}$ during spring and $15.5 \mathrm{~dB}$ during summer, during the same percentage of time. Hence, the lowest attenuation is seen to occur in winter and therefore the highest gain. 
(a)

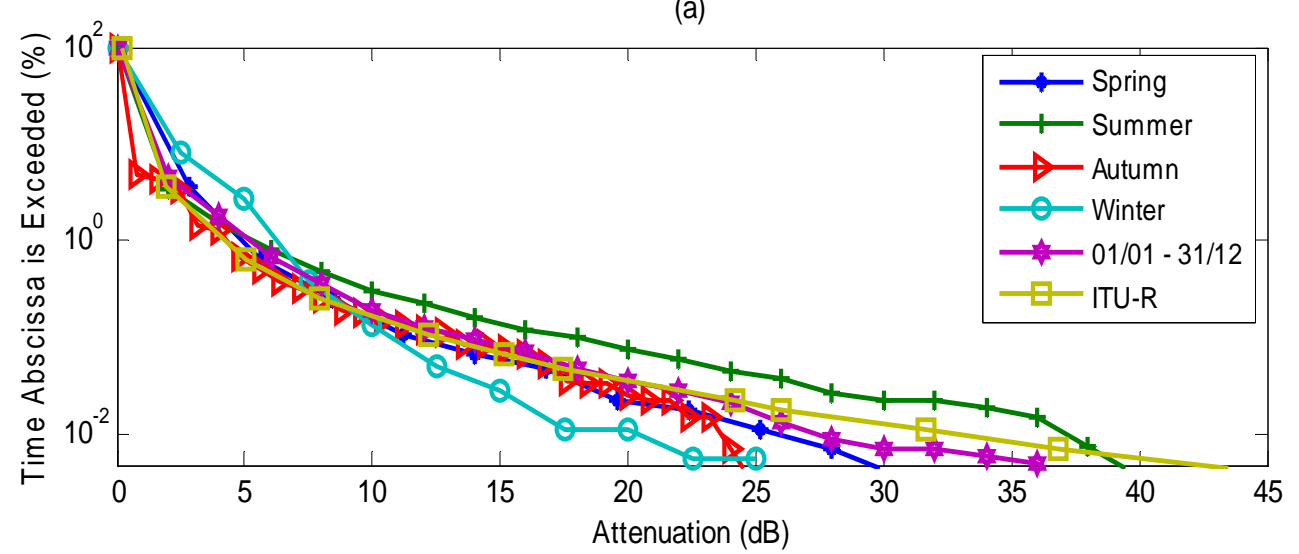

(b)

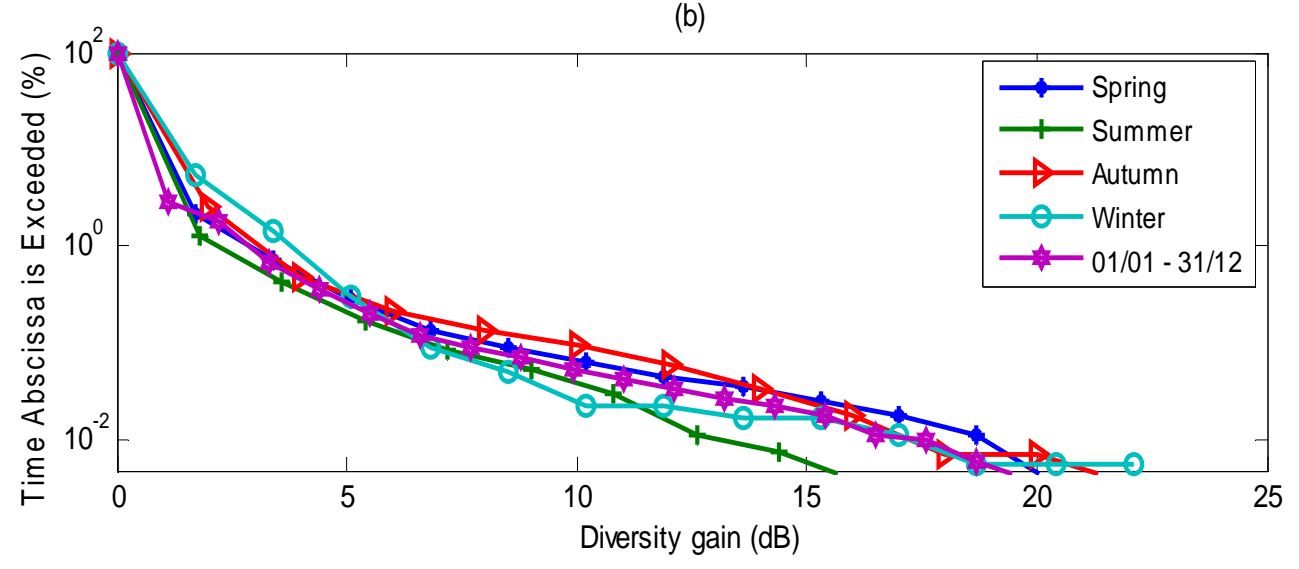

Fig. 5: Yearly and seasonal CDF of (a) Rain attenuation, and (b) Cell Site diversity gain

\section{Seasonal variations with angular separation}

Further analysis is carried out for each season by varying the angular separation between the sites. Fig. 6 to 9 show the CDF of each season for various angular separations. In concurrence with the overall diversity gain pattern observed during the various seasons, the figures show similar trend with maximum gain observed during winter with least gain in summer. It is observed that for shorter distances the correlation between various diversity sites is prevalent, as shown in the figures. This leads to the conclusion that differences in seasonal trends are exhibited during larger distance which is greater than $2 \mathrm{~km}$. At low separation distance of $2 \mathrm{~km}$ the likelihood of correlation in rain attenuation is high, thus larger distances show greater seasonal variations. The work reported by Otung et al. [10] suggests that the seasonal trend is due to a predominance of convective rainfall during summer, which has been reported to have a limited spatial extent of about $10 \mathrm{~km}$ and the occurrence of stratiform rain with larger spatial extent during the other seasons. 


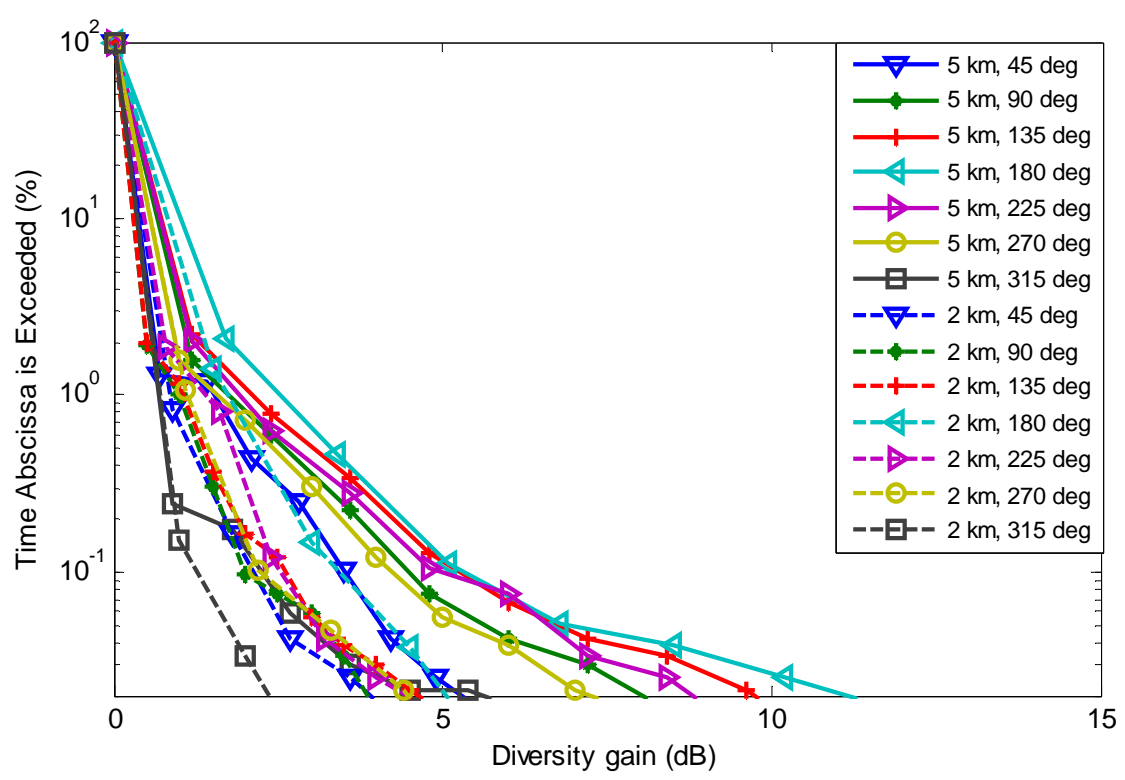

Fig. 6: CSD gain distribution for Spring

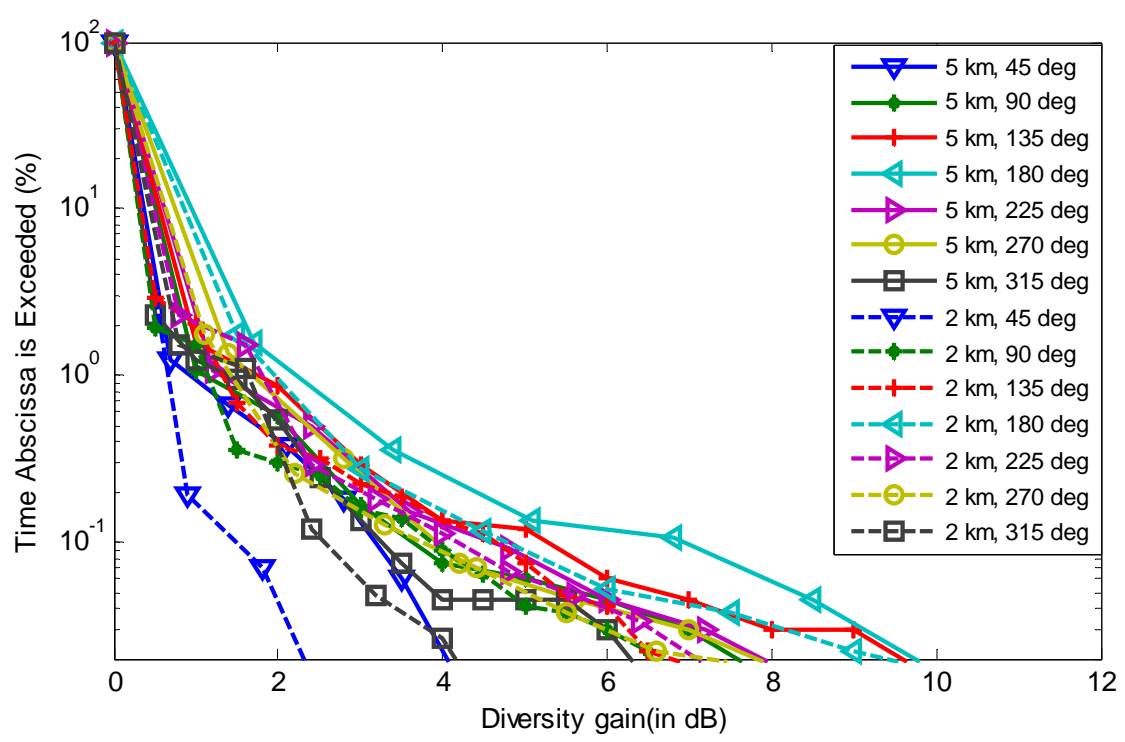

Fig. 7: CSD gain distribution for Summer

The patterns of the diversity gain distributions clearly indicate an increasing in CSD gain with increased separation distances. It is observed that the diversity gain has strong bearing on the azimuth angle at which the diversity site is located from the reference site. The results indicate that as the angular separation increases, the diversity gain increases. So with increasing azimuth from $0^{\circ}$ to $180^{\circ}$ there is increased CSD. The maximum CSD gain is observed at $180^{\circ}$ azimuth angle, which is considered the optimum angular separation between two sites in obtaining the maximum CSD gain. This is due to the fact that there is less likelihood of rain occurring in an opposite direction to the reference site. After $180^{\circ}$, the gain continues to reduce till it reaches $360^{\circ}$ point. So the angles that are in symmetric angular separation tend to show approximately equal CSD gain. The three pairs of angles that show similar gains are, $45^{\circ}$ and $315^{\circ}, 90^{\circ}$ and $270^{\circ}, 135^{\circ}$ and $225^{\circ}$ - with each pair differing from the reference site at $0^{\circ}$ azimuth by $45^{\circ}, 90^{\circ}$, and $135^{\circ}$. The work by Hendrantoro et al. [17] suggests that the angular separation of $108^{\circ}$ is acceptable as this can contribute to a slight reduction in gain. However, the current work suggests that there is a significant change in gain increasing up to $4 \mathrm{~dB}$ at $180^{\circ}$ compared to $108^{\circ}$ at $54 \mathrm{GHz}$ for 5 km separation. 


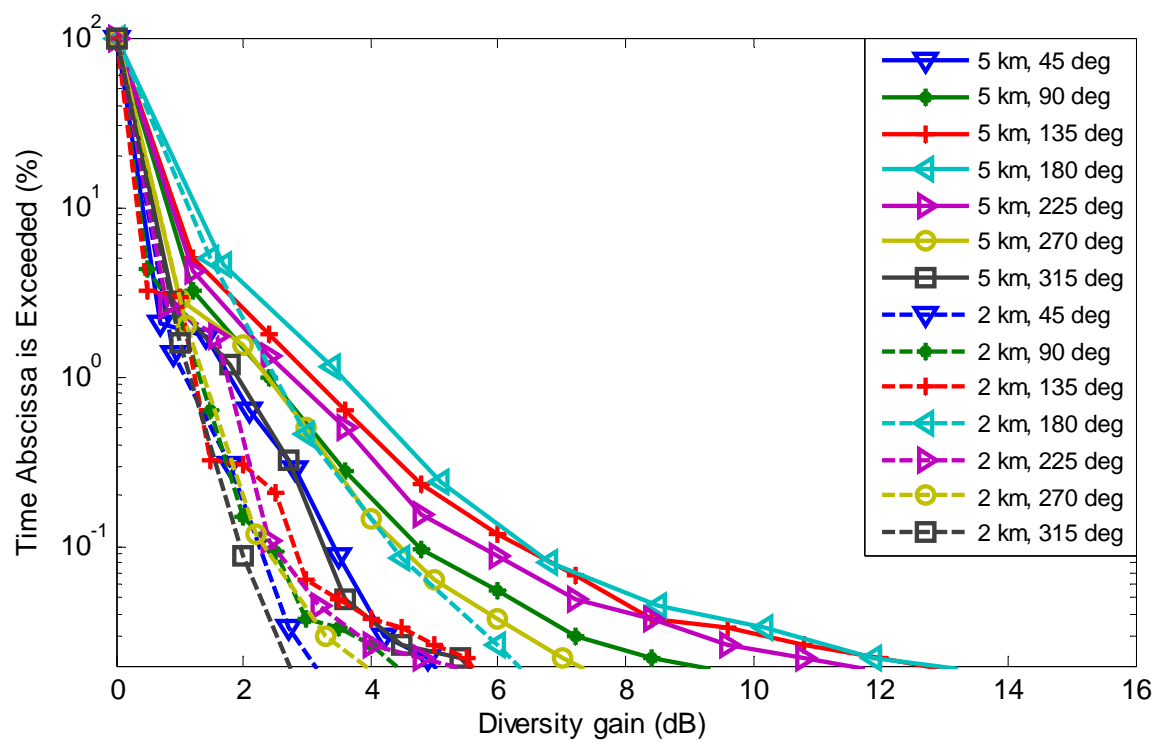

Fig. 8: CSD gain distribution for Autumn

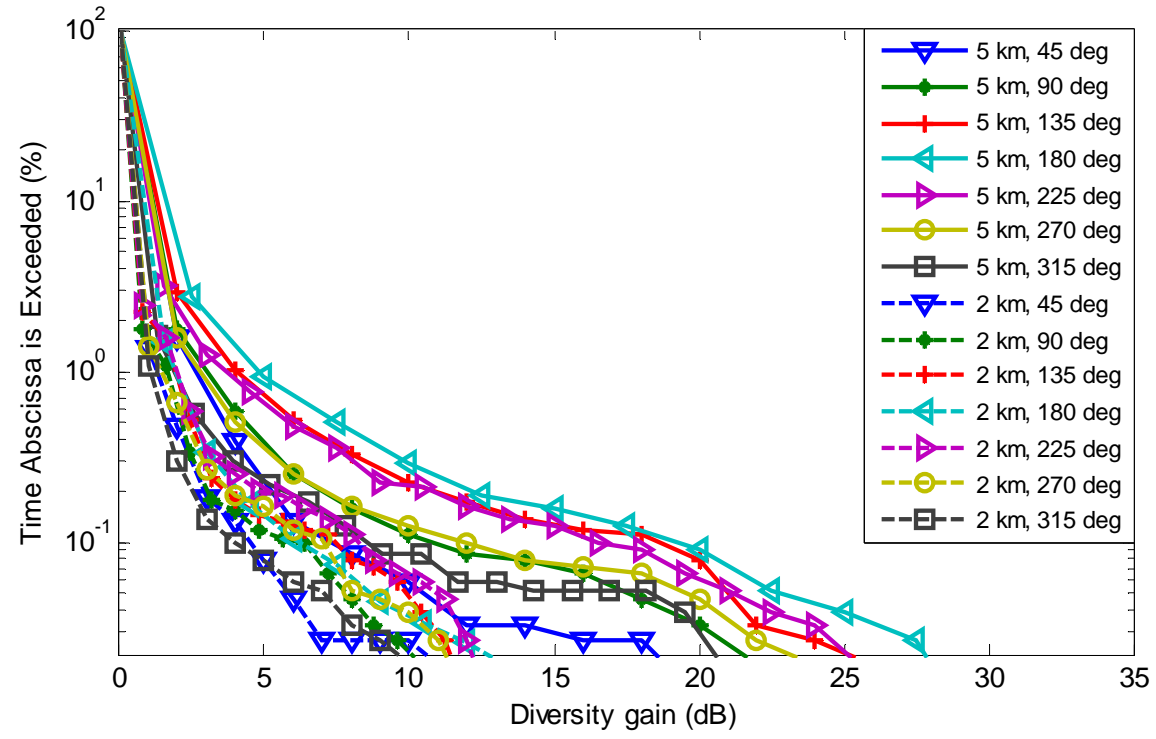

Fig. 9: CSD gain distribution for Winter 


\section{CONCLUSION}

Rain attenuation is a significant propagation impairment for a fixed LOS WiMAX link. In this paper a detailed analysis of CSD gain for frequencies extending from $20 \mathrm{GHz}$ to $54 \mathrm{GHz}$ which is optimum for the LOS operation at various seasons of a year is carried out. The work is extended at various combinations such as separation distances, and various azimuth angles. The results suggest that an increase in link distance provides increased CSD gain. The diversity sites also provide strong correlation in the presence of small azimuth angles. The optimum angular separation is obtained at $180^{\circ}$, the point providing maximum CSD gain. The diversity gain shows significant variations during various seasons and the order in which the gain increases is summer, spring, autumn and winter, during which the CDF of attenuation decreases in the same order. The seasonal distribution suggests that there is significant variation in the CSD performance with link distances greater than two kms.

\section{REFERENCES}

[1] O.A.Alim and Naggary, "Performance of MIMO antenna techniques on IEEE 802.16e," in ITI 5th International Conference on Information and Communications Technology, 2007, pp. 289-295.

[2] Jen-Ming Wu and Lin, "Channel Estimation for Non-Line-of-Sight WiMAX Communication System," in IEEE 63rd Vehicular Technology Conference, VTC 2006, 2006, pp. 2671-2675.

[3] F.Fedi, "Prediction of attenuation due to rainfall on terrestrial links," Radio Science, vol. 16, pp. 731-743, 1981.

[4] N.A.Perez Garcia and Mello, "Improved method for prediction of rain attenuation in terrestrial links," IEE Electronic letters, vol. 40, 2004.

[5] D. C. Hogg, "Path diversity in propagation of millimeter waves through rain", IEEE Transactions on Antennas and Propagation, vol. AP-15, p 410-415, May 1967.

[6] I. S. Usman, M. J. Willis and R. J. Watson, "Route diversity analysis and modelling for millimetre wave point to multipoint systems, Cost Action 280 Propagation impairment mitigation for millimetre wave radio systems, July 2002.

[7] Design of the HYREX rain gauge network, Hydrology and Earth System Sciences, Moore, R. J., D. A. Jones, D. R. Cox and V. S. Isham, vol. 4 issue 4, p 523-530, 2000.

[8] Specific attenuation model for rain for use in prediction methods, International Telecommunication Union Radiocommunication Assembly, Recomm. ITU-R P.838, International Telecommunication Union, Geneva, Switzerland, 2005.

[9] Propagation data and prediction methods required for the design of terrestrial line-of-sight systems, International Telecommunication Union Radiocommunication Assembly, ITU-R P.530-11, Geneva, Switzerland, 2005.

[10] I.E.Otung and C.Nagaraja, "Seasonal variation of site diversity performance," IEE Electronic letters, vol. 45, pp. 724-725 2009.

[11] S.Zvanovec and P.Pechac, "Simulations of site diversity based outage improvements for point to multipoint systems in millimeter wave band," in IEEE Wireless Telecommunications Symposium, 2005.

[12] Enoch S, Otung I.E. "Use of Cell-Site Diversity to Mitigate Rain Attenuation in 10-66 GHz Fixed WiMAX", $11^{\text {th }}$ IEEE International Conference on Wireless and Mobile Computing, Networking and Communications (WiMOB), Abu Dhabi, UAE, 19-21 October 2015, pp. $175-180$.

[13] M.Meinesz, F.Schoute, and J.D.Bakker, "A fixed network design for site diversity enhanced wireless access," in IEEE Vehicular Technology Conference, 1999, pp. 1033 - 1037.

[14] A.D.Panagopoulos and J.D.Kanellopoulos, "Cell site diversity performance of millimeter wave fixed cellular systems operating at frequencies above $20 \mathrm{GHz}$," IEEE antennas and wireless propagation letters, vol. 1, pp. 183-185, 2005.

[15] K.P.Liolis, A.D.Panagopoulos, and P.G.Cottis, "Use of cell-site diversity to mitigate co-channel interference in 10-66 GHz broadband fixed wireless access networks," in IEEE Radio and Wireless Symposium, 2006, pp. 283 - 286.

[16] G.Hendrantoro, R.J.C.Bultitude, and D.D.Falconer, "Use of cell site diversity in millimeter wave fixed cellular systems to combat the effects of rain attenuation," IEEE journal on selected areas in communications, vol. 20, pp. 602-614, 2002.

[17] G.Hendrantoro, D.Falconer, R.Bultitude, and I.Zawadzki, "Estimation of cell area coverage and cell site diversity gain under rainy conditions in $30 \mathrm{GHz}$ fixed wireless cellular systems using radar measurements," in Proc. URSI General Assembly, Netherlands, 2002.

[18] B.Heder, R.Singliar, and J.Bito, "Site diversity examination based on rain attenuation measurement," in 47th International Symposium ELMAR, 2005, pp. $357-360$.

[19] "Propagation data and prediction methods required for the design of terrestrial broadband millimetric radio access systems operating in a frequency range of about 20-50 GHz," Recommendations of the ITU-R, vol. P.1410-2, 2003.

[20] I. S. Usman, B.P.Lindhom, and Willis, "Rain fade countermeasure prediction and performance for millimetre broadband fixed wireless communication systems," in ICAP Conference, 2003.

[21] J.Tan and L.Pederson, "Study of simultaneous coverage and route diversity improvement under rainy periods for LMDS systems at 42 $\mathrm{GHz}, "$ in Proceedings of millennium conference on antennas and propagation, 2000.

[22] K.H.Craig, S.Hurley, and T.Tjelta, "Propagation studies for enhanced broadband wireless access," in URSI General Assembly, Maastricht, 2002.

[23] S.Zvanovec and P.Pechac, "Simulations of site diversity based outage improvements for point to multipoint systems in millimeter wave band," in IEEE Wireless Telecommunications Symposium, 2005.

[24] M.Cheffena, L.E.Braten, and T.Ekman, "On the space time variations of rain attenuation," IEEE transactions on antennas and propagation, vol. 57, pp. 1771-1782, 2009.

[25] S.J.Wood, D.A.Jones, and R.J.Moore, "Accuracy of rainfall measurement for scales of hydrological interest," Hydrology and Earth System Sciences, vol. 4, pp. 531-543, 2000.

[26] "Characteristics of precipitation for propagation modelling," ITU-R P.837-5, 2007.

[27] O.Fiser and D.Rezacova, "Rain measurement for improved propagation modelling in Czech republic," in The Second European Conference on Antennas and Propagation, 2007, pp. 1-7. 


\section{AUTHOR PROFILE}

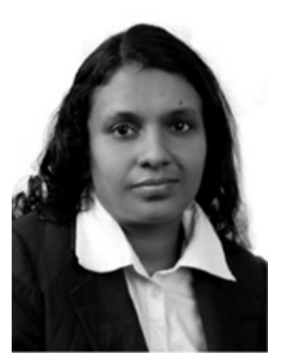

Sharmini Enoch received her Bachelor of Engineering (B.E.) in Electronics and Communication Engineering from Manonmanium Sundaranar University. Subsequently, she graduated her Master of Science (M.Sc.) in Electronics and Information Technology and Ph.D. from University of South Wales (USW, formerly University of Glamorgan), U.K. While pursuing her Ph.D., she was awarded a research scholarship from the Faculty of Advanced Technology, USW, U.K in 2006. She has worked as a lecturer in the USW for a period of 5 years and subsequently as Professor and Deputy Head of the Department in the Department of Electronics and Communication, Noorul Islam University, India for over 3 years. She worked as the Deputy project director for Noorul Islam University student nano-satellite project which was the Indian Space Research Organization (ISRO) space program. She was supervising the work carried out by students in Telemetry, Tracking and Tele-command (TTC) subsystem, Onboard computer and Communication subsystem. The design, fabrication and testing were held by the students of the university in collaboration with ISRO and industries. Currently she works as the Senior Technical Consultant of Doctors Academy, UK and Visiting Professor of Noorul Islam University where she supervises $5 \mathrm{Ph} . \mathrm{D}$. scholars. Her research interests include, broadband wireless access, radio wave propagation, fade mitigation techniques, digital communication and wireless networks. She has got several publications in International Journals and conference proceedings.

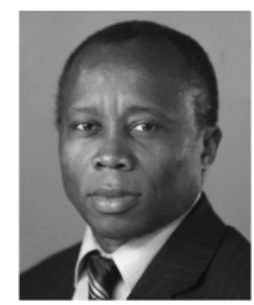

Ifiok E. Otung is Professor of Satellite Communications at the University of South Wales (USW, formerly University of Glamorgan). He earned the degrees of BSc (First Class Honours) and MSc in Electronic \& Electrical Engineering from the University of Ife Nigeria, and $\mathrm{PhD}$ in Satellite Communications from the University of Surrey, UK. Since 1997 he has been at USW where he teaches courses in Satellite, Mobile and Digital Communications and has supervised over 100 postgraduate research projects.

Prof Otung is a Chartered Engineer with broad and international experience of research and teaching at various universities in Europe and Africa. He has trained students of many nationalities and served as External Examiner of both undergraduate and $\mathrm{PhD}$ work at Universities in the UK, Asia and Africa. He has worked as a consultant for several research establishments and run short courses attended by engineers from leading companies and organisations in Europe. He also manages the MSc program in Mobile and Satellite Communications at USW.

Prof Otung researches in the areas of Mobile \& Satellite Communication Systems and Radiowave Propagation where he has over 120 publications and regularly reviews technical articles and textbooks for some of the world's leading academic publishers. Ifiok's best known work is the 664-page textbook titled Communication Engineering Principles, ISBN 0333 77522 8, which is used in leading Engineering Departments around the world. Prof Otung is also the author of the 520-page textbook, Digital Communications Principles and Systems ISBN 978-1849196116, recently published by the IET (Institution of Engineering and Technology) London, which seeks to give advanced undergraduates, postgraduates and practicing engineers in-depth expertise in the core principles of digital transmission and a complete understanding of the significance and interplay of the design parameters involved in digital communication systems. 